\title{
Research on the Optimization Direction of Tax Policy Based on the Perspective of Industrial Structure Adjustment
}

\author{
Weishuang $\mathrm{Xu}^{1, \mathrm{a} \text {, * }}$ \\ ${ }^{1}$ College of Economics and Management, Qilu Normal University, Jinan, Shandong, China \\ axwsjn@163.com
}

Keywords: Industrial Structure; Tax Policy; Optimization Direction; Optimization Strategy

\begin{abstract}
Economic structure adjustment with the core of industrial structure adjustment is the core of realizing the transformation of China's economic development mode. Market and government are the effective means to realize industrial structure adjustment. Due to the existence of market failure, the government's macro-control is essential. In the industrial structure adjustment, fiscal policy is superior to monetary policy, especially after large-scale fiscal expenditure policy, tax policy has become a key factor of affecting industrial resources allocation. Based on this, this paper first intends to analyze the direction of China's industrial structure adjustment and the function mechanism of tax policy on industrial structure adjustment, and then discusses China's tax policy optimization direction from tax structure, tax burden, tax incentives and other aspects.
\end{abstract}

\section{Introduction}

In recent years, China's economic development speed attracts global attention and international influence continues to improve. But the good economic development momentum can not cover up the problems existing in the economic development. Among these, structural problem becomes the most important problem. Guo Ke-sha (1999) [1] believes that the main factor of restricting China's economic growth is the structural problem rather than the total amount. The structural deviation has affected the efficiency and stability of China's economic growth. Therefore, "adjust structure, promote transformation" has become the focus of government work. Adjust structure involves all aspects. Specific to economic structure adjustment, industrial structure adjustment is the core and market and government are the effective means to realize industrial structure adjustment. Due to the existence of market failure, the government's macro-control is essential. In the industrial structure adjustment, fiscal policy is superior to monetary policy (Li Jun-ying and Su Jian, 2013) [2], especially after large-scale fiscal expenditure policy, tax policy has become a key factor of affecting industrial resources allocation. Therefore, research tax policy optimization direction based on the perspective of industrial structure adjustment direction is helpful to speed up the process of industrial structure adjustment in China.

\section{Tax Policy and Industrial Structure Adjustment}

The Relationship between Tax Policy and Industrial Structure Adjustment. The change of industrial structure will lead to the change of tax structure, tax revenue structure and tax burden structure, which will result in the change of tax system structure. Tax structure can affect industrial structure change by influencing the quantity or structure of tax revenue and further promote or hinder the smooth evolution of industrial structure (Zhang Jun and Tao Guang-ze, 2015[3], Liu Ying, 2014[4]). Combined with the relationship between tax policy and industrial structure, different scholars have mainly studied the influence of tax policy on industrial structure adjustment. Dagmar and Anwar shah (1992) [5] believe that the implementation of tax incentives is conducive to the rationalization and supererogation of industrial structure. Li Wen (2005)[6] believes that the macro tax burden level or structure changes will change private and government investment demand or consumption demand proportion, which led to the changes in the industrial structure and the internal structure of each industry. Luo Fuzheng and Luo Nengsheng (2016) [7] believe that the 
reasonable size macro tax burden is conducive to the supererogation and rationalization of industrial structure. Chu De-yin and Ji Fan (2017)[8] believe that commodity tax and income tax are conducive to the adjustment of industrial structure on the whole, but the incentive effect of income tax is relatively more obvious, especially the positive effect of individual income tax on the industrial structure adjustment is relatively better than the corporate income tax. Yu Xue (2017) [9] further argues that the tax policy has a lagging trend in the industrial structure adjustment. In the long run, the influence of turnover tax on industrial structure adjustment is more significant than that of income tax and the influence of both are positive. In the short term, the influence of income tax on industrial structure adjustment is stronger than turnover tax and the influence of both are negative. Chu De-yin and Jian Ke-cheng (2014)[10] and Shen Kun-rong, and Yu Hong-yan (2014)[11] believes the absence of China's tax system arrangement restricts the industrial structure adjustment. The tax structure mainly based on turnover tax and the unreasonable tax burden strengthen the imbalance of industrial structure.

In summary, although there are differences in the research perspective of different scholars, but in the following aspects basically reached a consensus: (1) Reasonable tax policies are conducive to the adjustment of industrial structure and the unreasonable tax policies will lead to the imbalance of industrial structure. (2) Tax system structure, tax burden level and tax incentives are the main ways that tax policy influence the adjustment of industrial structure. (3) Turnover tax and income tax are the two major tax systems that affect the adjustment of China's industrial structure, but there are differences between turnover tax and income tax in terms of influence, time and direction. (4) China's current tax policy arrangements have flaws which affect the realization of industrial structure adjustment objectives. There is still further optimized space for tax policy arrangement.

The Function Mechanism of Tax Policy on Industrial Structure Adjustment. Chu De-yin and Jian Ke-cheng (2014) believe that tax policy through output effect and substitution effect plays an important role in industrial structure: (1) Adjust the distribution of tax burden in different industries. (2) Affect consumption, investment and market resources allocation through the differentiated tax structure. (3)Influence industrial structure adjustment through tax incentives policies for a particular industry. Liu Ying (2014) believes that tax system can guide the behavior of enterprises and individuals through tax categories, tax base, tax rates and tax incentives and ultimately achieve the goal of transformation and upgrading of industrial structure. It can be seen that the government can directly or indirectly change the after-tax price of an industrial product and the comparative income of some investment behavior through the tax structure, tax burden and tax incentives, thus affecting the supply and demand of the product and the behavior of relevant stakeholders. And thus promote the adjustment of industrial structure.

\section{The Present Situation and Adjustment Direction of China's Industrial Structure}

The Present Situation of China's Industrial Structure. According to the data provided by "China Statistical Yearbook 2016", the ratio of China's tertiary industry in 2015 is 8.9:40.9:50.2 and the third industries accounts for more than $50 \%$ of the total for the first time. However, the overall industrial structure of China is not optimistic. (1) China's industrial structure is still at a very low level, especially the situation of high proportion and low-level of the second industry and the lower proportion of the third industry has not fundamentally changed. Which restrict the sustainable development of economy (Shen Kun-rong and Xu Li-bo, 2014) [12]. (2) In 2013, China's third industry GDP accounted for the proportion of tertiary industry GDP was $46.1 \%$, for the first time more than the second industry 2.2 percentage points. However, in those days, China was the only country in the BRICs countries that the third industry accounted for the proportion of GDP less than $50 \%$. Although China's third industry accounted for the proportion of GDP more than 50\% in 2015, but there is still a big gap compared with developed countries with a proportion of $70-80 \%$. (3)Between the tertiary industries and each industry internal structure is not harmonious. Economic growth depends too much on large-scale and low value-added manufacturing rather than advanced manufacturing and modern service industry. Energy consumption and environmental pollution problems are still prominent (Li Jun-ying and Su Jian , 2013). It can be seen that low level of 
industrial structure, the lack of coordination of tertiary industries and each industry internal structure, the underdevelopment of advanced manufacturing and modern service industries and environment pollution serious are the main problems existing in China's industrial structure.

The Adjustment Direction of China's Industrial Structure. The adjustment of industrial structure shows that the distribution of industrial quality changes from low level to advanced level and the process of transition from imbalance to coordination in quantity proportion. According to this law and the present situation of China's industrial structure, the direction of China's industrial structure adjustment can proceed from the following aspect. (1) Enhance the proportion of the third industry. Industrial upgrading, with the emphasis on increasing the proportion of the third industry, is the cause of China's sustained economic growth and also the result of the upgrading of the first and second industry. Therefore, in the industrial structure adjustment in the future, China should vigorously develop the third industry and realize the service of industrial structure by increasing the proportion of GDP in the third industry. (2) Optimize the internal industry structure of the second and third industries. In the second industry, give priority to the development of middle and high-end manufacturing industry and increase industrial added value. In the third industry, vigorously develop modern service industry. (3) Compress industries with high energy consumption, high pollution and excess capacity. Industries with high energy consumption, high pollution and industrial surplus have not only pulled down the utilization efficiency of China's resources but also affected the sustainable development of our economy. Therefore, the gradual compression of them is the mainstream trend.

\section{The Direction of Tax Policy Optimization in China}

While optimizing the economic structure, the tax structure must constantly optimize to adapt to the change of economic development mode, so as to serve the realization of industrial structure adjustment goal. Based on the perspective of industrial structure adjustment, changing the existing tax system structure, adjusting the tax burden level of different industries and strengthening the industrial tax incentives are the main directions of tax policy optimization in the future.

Optimize the Existing Tax Structure of China. Tax structure is the core of tax policy and also the first factor to be considered in the tax policy optimization in the future. (1) Adjust the proportion of turnover tax and income tax. China is a country with turnover tax and income tax as the main tax category, especially turnover tax is the absolute main tax in China. China's tax revenue more than $50 \%$ is contributed by turnover tax. Although in the long run, the impact of turnover tax on industrial structure adjustment is positive. But the turnover tax is an indirect tax and tax burden ultimately will be undertaken by the consumer. In the short term, it will cause imbalance between supply and demand and the failure of resource allocation, thus hindering the adjustment of industrial structure. Therefore, in the short term, the proportion of direct taxes with income tax as the main body should be considered to increase. Through these to regulate the gap between rich and poor, optimize industry structure and promote economic growth. (2) Reform resource tax and levy environmental protection tax. The resources tax and environmental protection tax is the main tax policy to solve the problems of low utilization rate of resources, serious environmental pollution and other issues caused by China's extensive economic growth. Through tax reform or levy new tax can improve the utilization efficiency of resources, reduce the backward production capacity and promote the sustainable economic development. Fortunately, China has comprehensively promoted the reform of resource tax on July 1, 2016 and the environmental protection tax law will come into effect on January1, 2018.

Guide the Effective Allocation of Resources through the Changes of Tax Burden Levels. Change the industrial tax burden level and thus affect the investment behavior of investment subject is the most effective and direct way to influence the industrial structure adjustment of tax policy. (1) Reduce the tax burden level of the third industry., The tax burden of many industries in China's third industry has not dropped but gone up after "replacing business tax with value-added tax", which has greatly increased the tax burden of industry development. Therefore, in the era after "replacing business tax with value-added tax", value-added tax should further play the role of 
neutral tax and also consider the specific circumstances of different industry in simplifying tax rate and integrating tax incentive policies, as far as possible to reflect on the low not high principles. (2) Raise the tax burden level of backward production capacity and excess production capacity. The formation of backward production capacity and excess production capacity is largely the result of government-led, so the solution of these problems also needs government's participation. For these industries, the tax burden can be increased by reducing tax incentives and levying new taxes, thereby guiding the outflow of production factors from these industries.

Strengthen Industry Tax Incentives and Achieve the Effective Docking of Industrial Chains. At present, many tax categories, especially the tax incentives of income tax are set up according to taxpayers and the region of taxpayers located. In addition to infrastructure and some industries encouraged by the state, very few tax incentives are based on the perspective of industry. Although this kind of tax incentive way considers taxpayer's affordability and regional economic development imbalance factors, but also easily lead to the unfair on other taxpayers and industrial structure homogeneity in different regions. This is not conducive to China's overall industrial structure adjustment. Therefore, government should pay more attention to industry tax fairness in the progress of tax policy formulating. Industry rather than taxpayer and region should be the primary factor to be considered in the progress of tax incentives formulating, so as to achieve effective docking of industry chain.

\section{Reference}

[1] Guo Ke-sha. Total Amount or Structure Problems?--the Restriction of Industrial Structure Deviation to Economic Growth and Its Adjusting Thinking [J]. Economic Research, 1999(09).

[2] Li Jun-ying and Su Jian. Structural Reduction Tax Policy from the Perspective of Economic Structure Adjustment [J]. Taxation Research, 2013(02).

[3] Zhang Jun and Tao Guang-ze. Tax Structure, Industrial Structure and Economic Growth: an Empirical Study Based on PVAR Model [J]. Journal of Zhengzhou Institute of Aeronautical Industry Management, 2015(04).

[4] Liu Yiing. Research on Industrial Transformation and Upgrading and Tax System: from the Perspective of Industrial Competitiveness of Economic Globalization [D]. Jiangxi University of Finance and Economics Doctoral Dissertation, 2014.

[5] Dagmar Rajagopal and Anwar Shah. Tax Incentives, Market Power and Corporate Investment [J]. Country Economic Department, the World Bank, 1992(908).

[6] Li Wen. Industrial Structure Tax Policy: Theory and Practice [D]. Jinan: Shandong University Doctoral Dissertation, 2005.

[7] Luo Fu-zheng, Luo Neng-sheng. How Does the Tax Burden Affect the Adjustment of Industrial Structure? - Based on the Discussion of Tax Burden Level and Scale [J]. Industrial Economics Research, 2016(01).

[8] Chu De-yin, Ji Fan. Changes in Tax Structure and Industrial Structure Adjustment: Theoretical Interpretation and Empirical Evidence in China [J]. Economist, 2017(03).

[9] Yu Xue. Analysis of the Impact of Tax System Structure on Industrial Structure [D]. Hangzhou: Zhejiang University of Finance and Economics, 2017.

[10]Chu De-yin, Jian Ke-cheng. Fiscal Policy and Industrial Structure Adjustment-an Empirical Analysis Based on the Dual Perspective of Total and Structural Effects [J]. Economist, 2014(02).

[11] Shen Kun-rong, YU Hong-yan. the Impact of Tax System Arrangement on Industry Structure [J].Economic Review, 2014(02).

[12] Shen Kun-rong, Xu Li-bo. China's Industrial Structure Upgrading: Progress, Resistance and Countermeasures [J]. Academia Bimestrie, 2014(01). 